\title{
DNA barcodes, expanded distribution, and redescription of Apanteles hemara Nixon, 1965 (Hymenoptera, Braconidae, Microgastrinae), a potential biocontrol species against amaranth leaf-webbers in Africa
}

\author{
Jose Fernandez-Triana', Melanie Beaudin', Kees van Achterberg², \\ Mawufe K. Agbodzavu' ${ }^{3}$, Stephen T.O. Othim³, \\ Faith W. Nyamu ${ }^{3}$, Komi K.M. Fiaboe ${ }^{3}$
}

I Canadian National Collection of Insects, Ottawa, Canada 2 Naturalis Biodiversity Center, Leiden, Netherlands 3 International Centre of Insect Physiology and Ecology (ICIPE), Plant Health Unit, P. O. Box 30772-00100, Nairobi, Kenya

Corresponding author: Jose Fernandez-Triana (jose.fernandez@agr.gc.ca)

Academic editor: G. Broad | Received 21 April 2017 | Accepted 17 July 2017 | Published 31 August 2017

http://zoobank.org/FFB06F0A-4C95-463E-8171-4924E805DD31

Citation: Fernandez-Triana J, Beaudin M, van Achterberg K, Agbodzavu MK, Othim STO, Nyamu FW, Fiaboe KKM (2017) DNA barcodes, expanded distribution, and redescription of Apanteles hemara Nixon, 1965 (Hymenoptera, Braconidae, Microgastrinae), a potential biocontrol species against amaranth leaf-webbers in Africa. Journal of Hymenoptera Research 58: 1-15. https://doi.org/10.3897/jhr.58.13361

\begin{abstract}
The microgastrine parasitoid wasp Apanteles hemara Nixon, 1965, is currently being considered as a potential biocontrol agent of amaranth leaf-webber pests in Africa. To facilitate future research and identification of the species, we characterize it from an integrative taxonomy perspective by providing a comprehensive morphological redescription, extensive illustrations (including the first images of the holotype), DNA barcodes, wasp biology, host data (Choreutidae and Crambidae caterpillars), and updated geographical distribution of the species (including eight new country records). Despite a wide distribution across four major biogeographical regions (mostly within the Old World tropics), the species seems to be relatively uniform from a molecular and morphological perspective, based on studied specimens from Africa and Asia.
\end{abstract}

\section{Keywords}

Microgastrinae, Amaranthus, biocontrol, DNA barcode, geographical distribution, Africa

Copyright Jose Fernandez-Triana et al. This is an open access article distributed under the terms of the Creative Commons Attribution License (CC BY 4.0), which permits unrestricted use, distribution, and reproduction in any medium, provided the original author and source are credited. 


\section{Introduction}

Apanteles hemara was described more than 50 years ago (Nixon 1965), and even at that time it was considered to have a wide distribution. The species has been recorded from many countries: Australia, Bulgaria, Canary Islands, Cape Verde Islands, China, Cyprus, France, Greece, India, Iran, Israel, Italy, Madeira Islands, Mauritius, mainland Portugal, Russia, Senegal, South Africa, mainland Spain, Turkey, Vietnam, and the former Yugoslavia (Austin 1992, Papp 1988, 2007, 2012, Long and Belokobylskij 2003, Shaw 2012, Kedar and Kumaranag 2013, Madl and van Achterberg 2014, Yu et al. 2016).

The host species attacked by $A$. hemara are also varied: it has been considered a regular solitary parasitoid of Tebenna micalis (Mann, 1857) (Choreutidae), wherever both species occur (Shaw 2012), but it is also recorded from several species of Crambidae: Cnaphalocrocis trapezalis (Guenée, 1854), Herpetogramma stultalis (Walker, 1859), Hydriris ornatalis (Duponchel, 1832), Omiodes indicata (Fabricius, 1775), Spoladea recurvalis (Fabricius, 1775) and Udea ferrugalis (Hübner, 1796) (Long and Belokobylskij 2004, Papp 2012, Madl and van Achterberg 2014, Yu et al. 2016). The wasp may play some role in the biological control of caterpillars of $S$. recurvalis attacking amaranth crops in India, although the parasitism rate is low (Peter and Balasubramanian 1984, Velmurugan et al. 2006, Arivudainambi et al. 2010).

Due to the wide geographical distribution and host associations, the species was described four times under different names, and it currently has three synonyms (see below for more details on that).

In order to better characterize the species, this paper provides the first molecular information for Apanteles hemara (DNA barcodes), expands the known distribution to an additional eight countries, and presents the first color pictures of the species, including the holotype.

\section{Methods}

We studied specimens from the California Academy of Sciences (CAS), Canadian National Collection of Insects, Ottawa (CNC), the International Centre of Insect Physiology and Ecology, Nairobi, Kenya (ICIPE), and Naturalis Biodiversity Center, Leiden, Netherlands (RMNH).

Specimens from several countries (Kenya, Madagascar, Republic of the Congo, United Arab Emirates, and Yemen) were sampled for DNA barcodes (the 5' region of the cytochrome c oxidase I (CO1) gene, Hebert et al. 2003). DNA extracts were obtained from single legs using a glass fibre protocol (Ivanova et al. 2006). Total genomic DNA was re-suspended in $30 \mu \mathrm{l}$ of $\mathrm{dH} 2 \mathrm{O}$, a 658-bp region near the 5 ' terminus of the $\mathrm{CO} 1$ gene was amplified using standard primers (LepF1-LepR1) following established protocols (http://v4.boldsystems.org/index.php), and a composite sequence was generated for all successful amplifications. All information for the sequences associated 
with each individual specimen can be retrieved from the Barcode of Life Data System (BOLD) (Ratnasingham and Hebert 2007).

The holotype of $A$. hemara was photographed with a Leica DFC450 camera on a Leica M165 C microscope. Other specimens were photographed with a Keyence VHX-1000 Digital Microscope, using a lens with a range of 10-130 $\times$. Multiple images were taken of a structure through the focal plane and then combined to produce a single in-focus image. For the Leica camera, the Zerene Stacker program (http:// zerenesystems.com/cms/stacker) was used; software associated with the Keyence System produced focused images taken with that camera. Plates were prepared using Microsoft PowerPoint 2010.

A map with the distribution of the species was generated using SimpleMappr (Shorthouse 2010).

\section{Results}

\section{Apanteles hemara Nixon, 1965}

Apanteles hemara Nixon, 1965. Original description Nixon (1965: 58). Apanteles caboverdensis Hedqvist, 1965. Synonymized by Papp (2003). Apanteles proalastor Hedqvist, 1965. Synonymized by Papp (2003). Apanteles bulgaricus Balevski \& Tobias, 1980. Synonymized by Papp (1988).

Holotype. INDIA, Dehradun. Female (deposited in the Natural History Museum, London), examined.

Other material examined. DEMOCRATIC REPUBLIC OF THE CONGO: Iboubikro, Lesio-Loun Pk.; Pool, -3.2699 15.4711, 340mm, 25.xi.2008, coll. Braet \& Sharkey, voucher code: CNCH2805 (1 specimen, CNC); KENYA: Eastern Province, Ukasi, Base of Ukasi Hill, -0.8210 38.5440, 613mm, Malaise trap, 11.xii.2012, coll. R. Copeland, voucher codes: 14703BraC10, 14703BraC12 (2 specimens, R. Copeland personal collection); Yatta, $-1.230437 .4579,1184 \mathrm{~mm}$, reared, coll. ICIPE, voucher codes: CNC507541, CNC507542, CNC507543, CNC507544, CNC507545, CNC507546 (6 specimens, CNC); MADAGASCAR: Fianarantsoa, Parc National Ranomafana, Radio tower at forest edge, $-21.25147 .412,1130 \mathrm{~mm}, 2 . x i i .2006$, coll. Irwin \& Harin'Hala, voucher codes: CASENT2163191, CNC666410 (2 specimens, CAS); -21.2510 47.4120, 1130mm, 7.ix.2006, coll. Irwin \& Harin'Hala, voucher codes: CASENT2163390, CNC661376 (2 specimens, CAS); OMAN: Salalah, 17.00 54.06, 20m, 24.iv.1992, coll. M.D. Gallagher, voucher codes: CNC661377, CNC666409 (2 specimens, CNC); UNITED ARAB EMIRATES: Abu Dhabi, AlAjban, 24.6000 55.0167, Malaise trap, 7-28.xii.2006, coll. A. van Harten, voucher code: CNC666414 (1 specimen, CNC); Fujairah, Fujairah, 25.1333 56.350000, light trap, 13-29.xi.2005, coll. A. van Harten, voucher code: CNC666415 (1 specimen, CNC); NARC near Sweihan, 24.4 55.433, 20.iv.2005, coll. A. v. Harten, vouch- 
er code: CNCH2681 (1 specimen, CNC); Sharjah, Sharjah Desert Park, 25.2833 55.7000, 21-29.iii.2005, coll. A. van Harten, voucher code: CNC666413 (1 specimen, CNC); 25.283 55.7, 21.iii.2005, coll. A. v. Harten, voucher code: CNCH2674 (1 specimen CNC); 29.iii.2005, coll. A. v. Harten, voucher code: CNCH2675 (1 specimen CNC); 9.iii.2005, coll. A. v. Harten, voucher code: CNCH2678 (1 specimen CNC); YEMEN: $12 \mathrm{~km} \mathrm{NW}$ of Manakhah, Malaise trap, 15.ix-22.x.2003, coll. A. van Harten, voucher code: CNC666412 (1 specimen, CNC); Al Kowd, light trap, vii.2000, coll. A. van Harten \& S. Al Haruri, voucher code: CNC666411 (1 specimen, CNC); Al Lahima, 15.xii.2000, coll. A. v. Harten \& Hager, voucher codes: CNCH2690, CNCH2718, CNCH2723 (3 specimens, CNC); Malaise trap, 9.iv-5.vi.2001, coll. A. V. Harten, voucher code: CNC666406 (1 specimen, CNC); Al Mahrah, Al Ghaydah, 12-14.xi.1997, coll. A. Sallam \& S. Ba Angood, voucher code: CNC666405 (1 specimen, CNC); Sana'a, Malaise trap, ii-iii.1998, coll. A. van Harten, voucher code: CNC666408 (1 specimen, CNC); Seyun, light trap, xi.2002, coll. A.V. Harten, voucher code: CNC661375 (1 specimen, CNC); Ta'izz, light trap, 3-24.i.1999, coll. A.V. Harten \& M. Mahyoub, voucher code: CNC666407 (1 specimen, CNC); no specimen data, voucher code: WAM 0209 (1 specimen CNC).

Distribution. Afrotropical, Australian, Oriental and Palaearctic regions (Fig. 1). The species is widespread in the Old World tropics, especially Africa. We record here the presence of Apanteles hemara in eight additional countries. The new distribution records for Kenya, Madagascar, Republic of the Congo, United Arab Emirates, and Yemen are based on examined specimens from the CAS, CNC, ICIPE and RMNH collections. Additionally, three other countries (Egypt, Pakistan, and Saudi Arabia) are recorded based on BOLD records whose sequences match sequences of the species, although those specimens were not available to us for study. The new data expands the species distribution across mainland Africa (where it was already known from a few countries), to Madagascar and the Arabian Peninsula (where it had not been recorded before). Based on the specimens we examined, the species has been collected throughout the entire year.

Diagnosis. Apanteles hemara can be recognized by having antenna slightly shorter than body length, with flagellomere 14 length 1.3-1.6 $\times$ its width; vein R1 about four times as long as distance between ends of veins R1 and 3RS; hind legs with black coxa, yellow trochanter and trochantellus, brown metafemur, metatibia yellow on anterior $0.5-0.6$ and brown on posterior $0.4-0.5$, metatibial spurs white, and metatarsus brown; propodeum mostly smooth, but with entire areola entirely defined by strong carinae; tergites 1 and 2 with strong, longitudinal striation; and ovipositor sheats shorter than metatibia (0.7-0.9 $\times$ ). Apanteles hemara belongs to the ater species group (sensu Nixon 1965), which unfortunately comprises "many aggregates of species that are not closely related but merge into one another through transitional forms" (Nixon 1965: 25). The world species were keyed out by Nixon (1965), but many more species have been described since, and thus that paper is now outdated. Updates are available for species of the ater group from Europe (Papp 1980), the former Soviet Union (Tobias 1986), China (Chen and Song 2004) and Mesoamerica (Fernandez-Triana et al. 2014) but unfortunately there is no updated key to world species. 


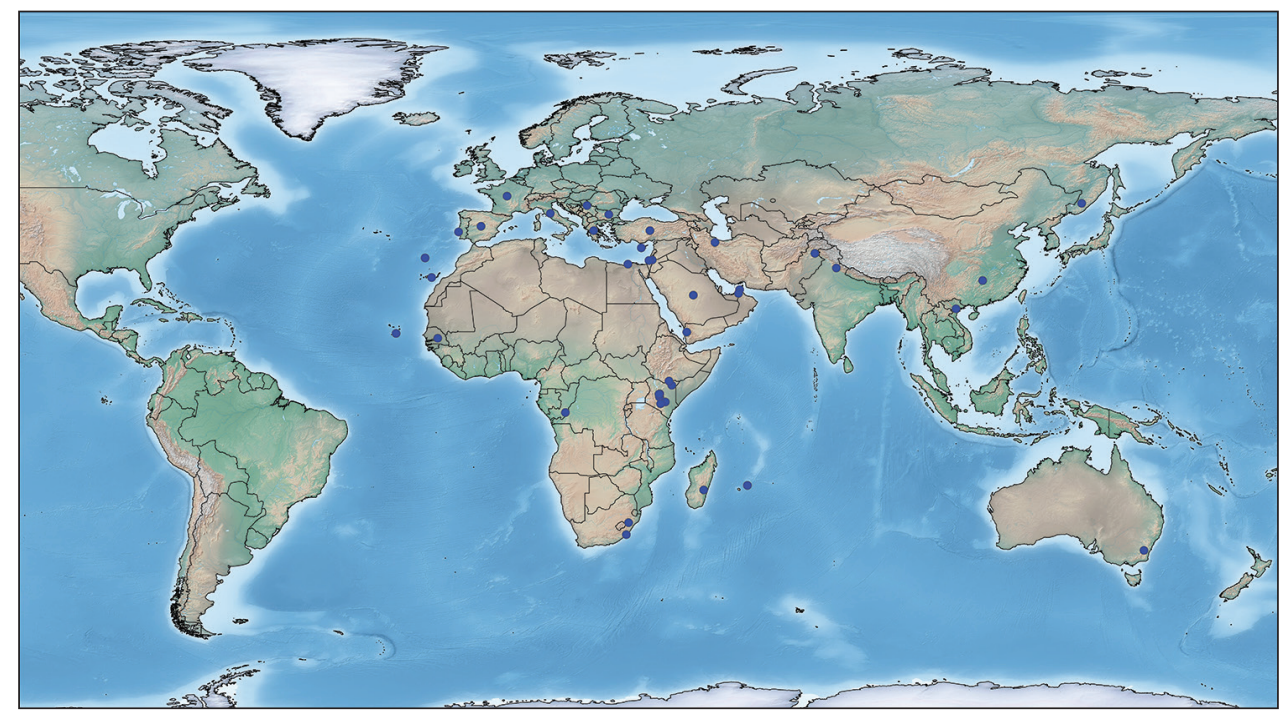

Figure I. Worldwide distribution of Apanteles hemara.

Redescription. Body color mostly black, tergites $3+$ dark brown, laterotergites and sternites $3+$ light yellow-brown. Head black, except for dark orange-brown labrum, light yellow-white palpi and dark brown antennae. Front and middle legs yellow (except for coxae and mesofemur light yellow-brown to brown); hind leg with black coxa, yellow trochanter and trochantellus, brown metafemur, metatibia yellow on anterior 0.5-0.6 and brown on posterior 0.4-0.5, metatibial spurs white, and metatarsus brown. Wings with most veins transparent or white, except for brown veins R1, r, 2RS and M; pterostigma mostly brown, with a very small white spot at base. Anteromesoscutum and scutellar disc with relatively coarse and dense punctures (distance between punctures smaller than diameter of individual puncture). Propodeum mostly smooth, with areola entirely defined by strong carinae. Tergites 1 and 2 with strong, longitudinal striation, contrasting with remaining tergites which are smooth. Body measurements (in mm) and ratios. Body length: $2.50-3.20$, fore wing length: 2.50-3.00, ovipositor sheaths: $0.62-0.84$, metafemur: $0.65-0.77$, metatibia length: $0.87-0.95$, tergite $10.36-0.49$. Length of flagellomeres: $1^{\text {st }}(0.18-0.22), 2^{\text {nd }}(0.18-$ $0.22), 3^{\text {rd }}(0.17-0.21), 14^{\text {th }}(0.08-0.10), 15^{\text {th }}(0.08-0.10)$ and $16^{\text {th }}(0.12)$. Length/ width of flagellomere 2: 2.75-3.14; length/width of flagellomere 14: 1.28-1.60. Head height/width: $0.82-0.88$; head slightly narrowing towards mandibles, width at clypeus base $0.88-0.88 \times$ head width at antennal base. Malar line 1.12-1.50 $\times$ mandibular base. Ocular ocellar line 1.67-2.00 $\times$ posterior ocellus diameter; interocellar distance 1.71-2.17 $\times$ posterior ocellus diameter. Scutellar disc length $1.09-1.15 \times$ width at base. Maximum height of mesoscutellum lunules $0.42-0.56 \times$ maximum height of lateral face of mesoscutellum. Tergite 1 widening from anterior margin to two thirds of tergite length, then slightly narrowing towards posterior margin; tergite 1 length 
1.64-2.09 $\times$ tergite width at posterior margin; tergite widths (at anterior margin/maximum width/posterior margin): $0.19-0.25 / 0.27-0.30 / 0.22-0.25$. Tergite 2 width at posterior margin $2.31-2.64 \times$ length medially. Tergite 2 length medially $0.48-0.64 \times$ tergite 3 length medially. Metafemur length 3.25-3.67 $\times$ metafemur width. Pterostigma length 2.55-2.86 its width. Vein R1 length 1.15-1.27 × pterostigma length. Vein r length $1.82-2.20 \times$ vein 2 RS length.

Variation. Despite the widespread distribution of the species across four major biogeographical regions (mostly Old World tropics), the specimens we examined were very similar morphologically (Figs 4-8), with only minor variation in the color of the hind legs and tergites $3+$ of the metasoma. However, we could not examine specimens from the Australian or the Palaearctic regions, which might be more variable than the specimens from Africa and Asia we studied.

Biology. Solitary parasitoid (Fig. 4E); over 41,280 parasitism cases were observed by us under laboratory condition at ICIPE in Kenya during a three years study. Hosts: Choreutidae, Tebenna micalis; Crambidae, Cnaphalocrocis trapezalis, Herpetogramma stultalis, Hydriris ornatalis, Omiodes indicatae, Spoladea recurvalis, Udea ferrugalis. For additional details see Comments below.

DNA barcodes. A total of 17 DNA barcodes were obtained from the specimens we studied. All sequences but one were over 600 base pairs (bp) long, with most representing full barcodes $(658 \mathrm{bp})$. Additional sequences representing the species are found in BOLD, but we could not examine those specimens because they belong to projects that are not public yet. Overall, there are currently 32 sequences belonging to $A$. hemara in BOLD, 24 of them being public records and 19 being barcode compliant (Fig. 2). The species has been assigned the BIN number BOLD:AAB1927 (for the concepts of 'BIN' and 'barcode compliant' see Ratnasingham and Hebert 2007). The DNA barcode intraspecific variation (p-distance) for $A$. hemara averaged $0.61 \%$ (4 $\mathrm{bp})$, with a maximum of $1.91 \%(12 \mathrm{bp})$, but more than half of the analyzed sequences differed by only $0.2-0.4 \%(1-2 \mathrm{bp})$. There were six different haplotypes recognized among the barcoded specimens. From a DNA barcode perspective, the nearest species in BOLD is Apanteles xanthostigma (Haliday, 1834), which differs from $A$. hemara by 6.93\% (45 bp) (Figs 2, 3).

Comments. In Kenya, the parasitoid was collected during outbreaks of two amaranth leaf-webber species, Spoladea recurvalis and Udea ferrugalis on two species of amaranth, Amaranthus cruentus L. and $A$. dubius L. It was successfully reared under laboratory conditions on both amaranth leaf-webber species at ICIPE. However, it failed to attack the leafworm species Spodoptera littoralis (Boisduval, 1833) and S. exigua (Hübner, 1808) (Noctuidae). During population dynamics studies carried out under field conditions at high and mid altitude levels in Central Kenya, field parasitism rates on $S$. recurvalis as low as 3\% were obtained during outbreak periods while parasitism rates as high as 25 to $75 \%$ were achieved outside outbreak periods. These observations prompted studies for potential augmentative biological control strategies for early interventions aiming at preventing or reducing outbreaks of the amaranth leaf-webbers in farmers' fields. Under laboratory conditions $\left(25 \pm 2{ }^{\circ} \mathrm{C}, 60 \pm 10 \% \mathrm{RH}\right.$ and $12 \mathrm{~L}: 12 \mathrm{D}$ 
DISTANCE DISTRIBUTION

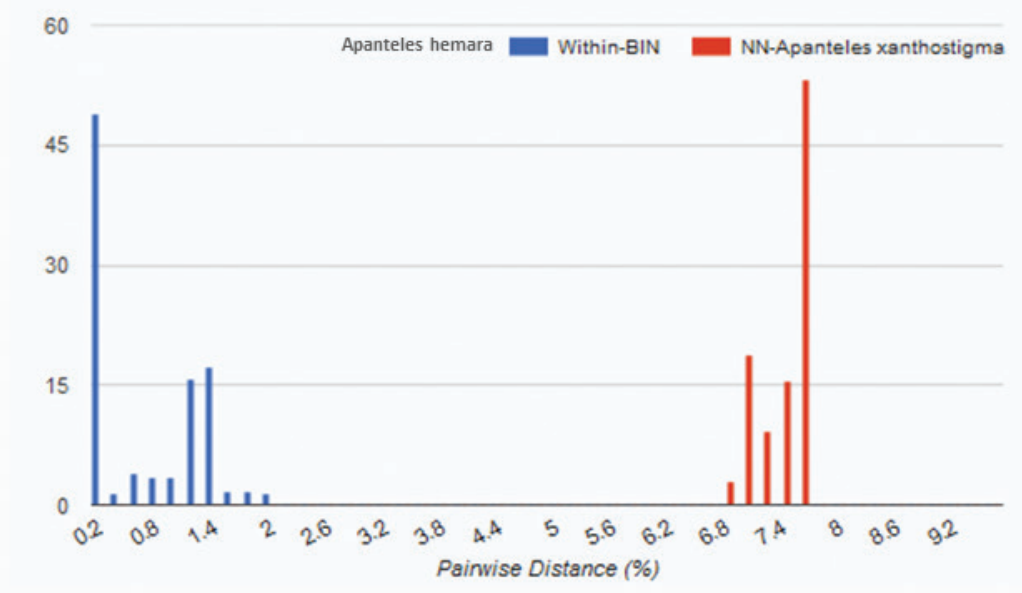

Barcode Index Number Registry For BOLD:AAB1927

Go to public records in this BIN

\section{BIN DETAILS}

\begin{tabular}{|c|c|c|c|}
\hline BIN URI: & BOLD:AAB1927 & Average Distance: & $0.61 \%$ (p-dist) \\
\hline DOI: & REQUEST DOI & Maximum Distance: & $1.91 \%$ (p-dist) \\
\hline Member Count: & 32 [24 Public] & $\begin{array}{l}\text { Distance to Nearest } \\
\text { Neighbor: }\end{array}$ & $6.93 \%$ (p-dist) \\
\hline $\begin{array}{l}\text { Barcode Compliant } \\
\text { Members: }\end{array}$ & 19 & & \\
\hline
\end{tabular}

\section{NEAREST NEIGHBOR (NN) DETAILS}

\begin{tabular}{|c|c|c|c|}
\hline Nearest BIN URI: & BOLD:AAB1922 & Average Distance: & $0.5 \%$ (p-dist) \\
\hline Member Count: & 28 & Maximum Distance: & $1.54 \%$ (p-dist) \\
\hline Nearest Member: & NOFIG607-15 & Distance Variance: & $0.17 \%$ (p-dist) \\
\hline $\begin{array}{l}\text { Nearest Member } \\
\text { Taxonomy: }\end{array}$ & $\begin{array}{l}\text { Arthropoda, Ins } \\
\text { Microgastrinae, }\end{array}$ & $\begin{array}{l}\text { menoptera, Braconic } \\
\text { les, Apanteles xanthc }\end{array}$ & gma \\
\hline
\end{tabular}

Figure 2. Details of the Barcode Index Number Registry for Apanteles hemara, data from BOLD (http:// v4.boldsystems.org/).

photoperiod), A. hemara demonstrated high performance on S. recurvalis and U. ferrugalis both through high direct parasitism rates and significant non-reproductive mortalities caused to the hosts. The parasitized caterpillars can easily be distinguished from 


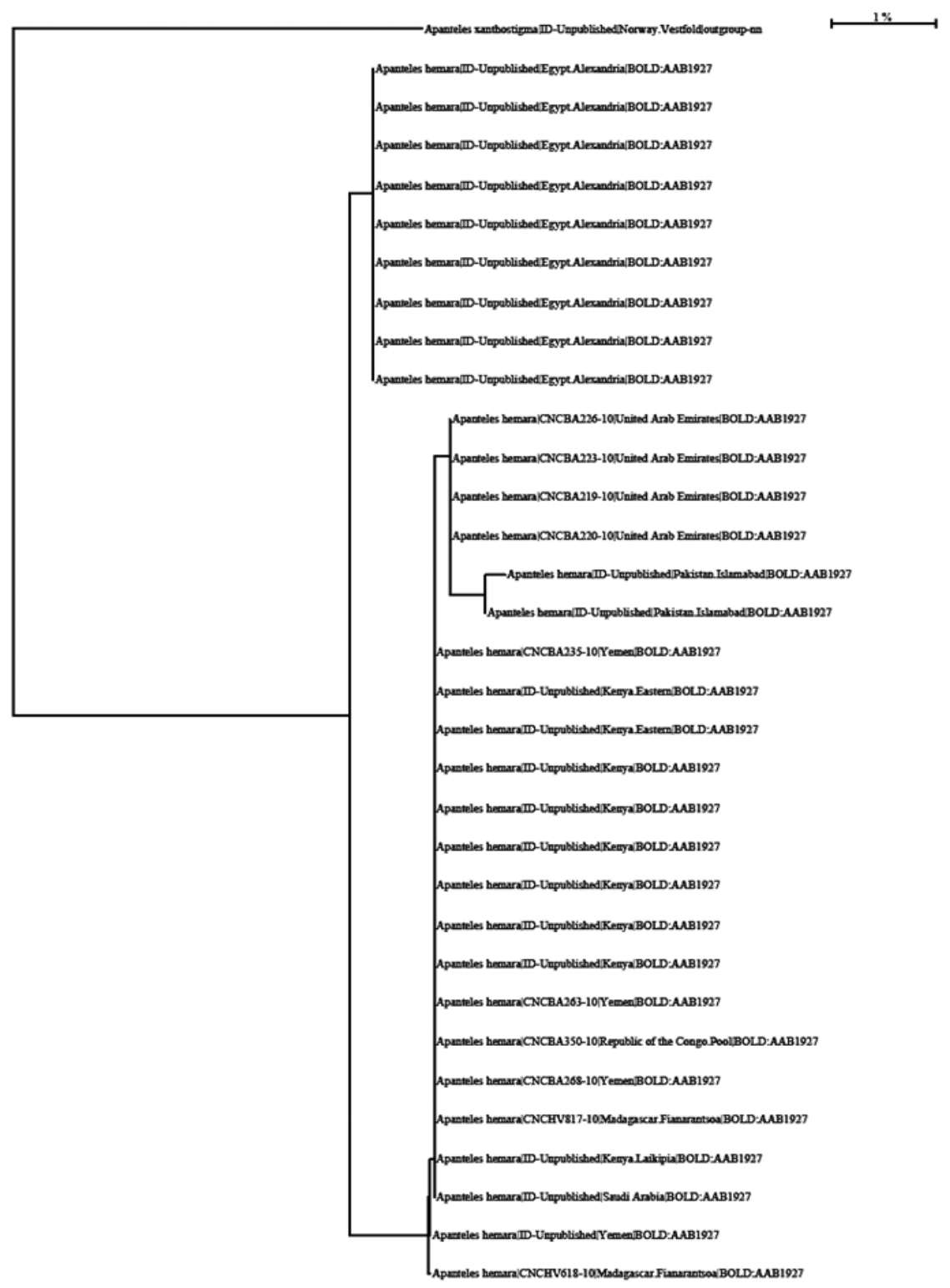

Figure 3. Neighbour Joining tree (K2P) of all known DNA barcoding sequences of Apanteles hemara and a representative of the closer species (Apanteles xanthostigma) in the BOLD database (as of April 2017).

non-parasitized ones within the first two days after the parasitoid's oviposition in the larva, through a significant reduction in feeding, movement and the lack of windowing on the leaf epidermis. Subsequently their growth rate is reduced and within four days after the parasitoid's oviposition, parasitized caterpillars are considerably smaller in size than their non-parasitized counterparts, turn creamish and will all die whether 

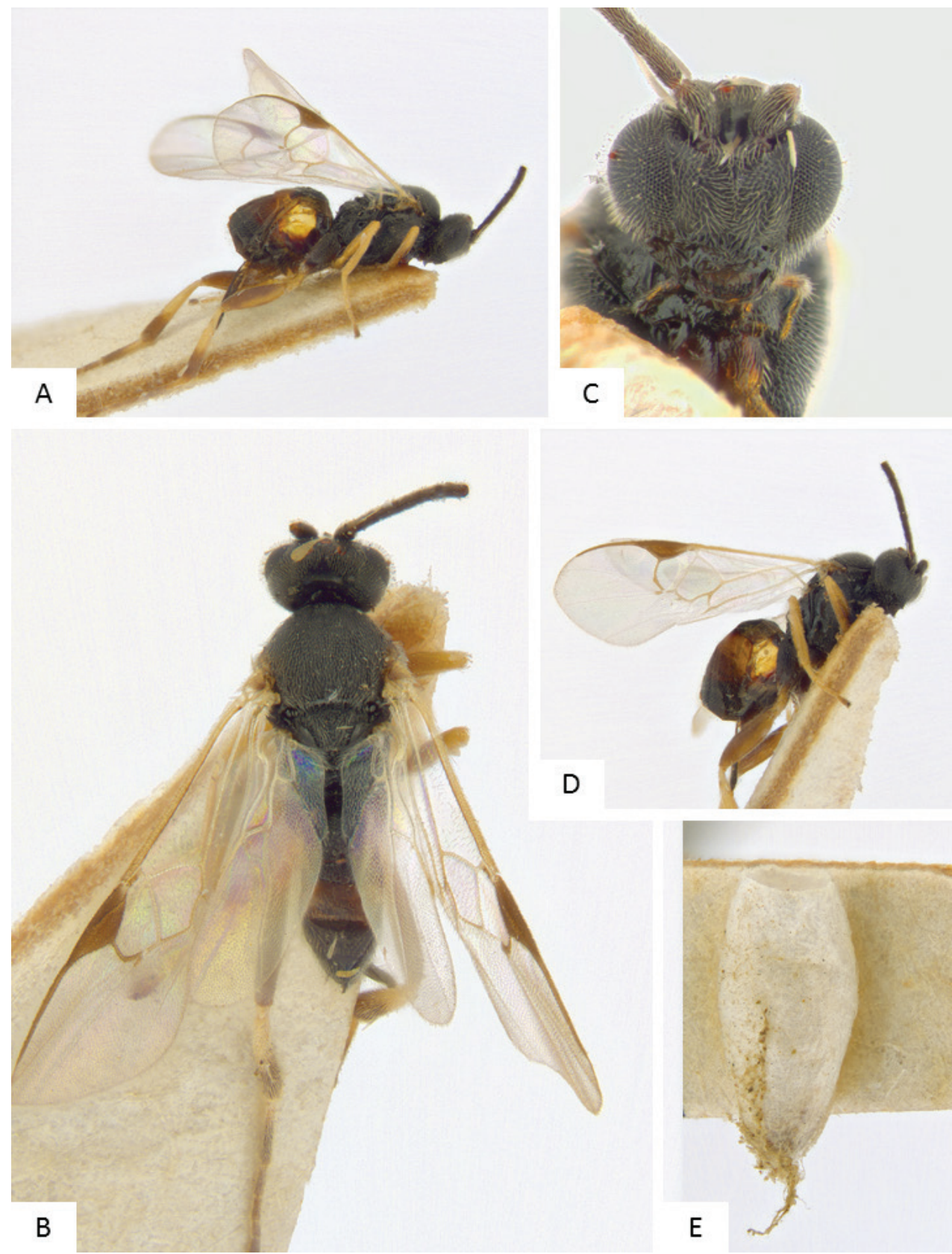

Figure 4. Apanteles hemara, female holotype from India.

the parasitoid successfully emerged or not. The developmental times are 12 and 13 days for male and female parasitoids respectively. Apanteles hemara is currently being considered for a conservative and augmentative biological control program against the amaranth leaf-webbers in Africa. 


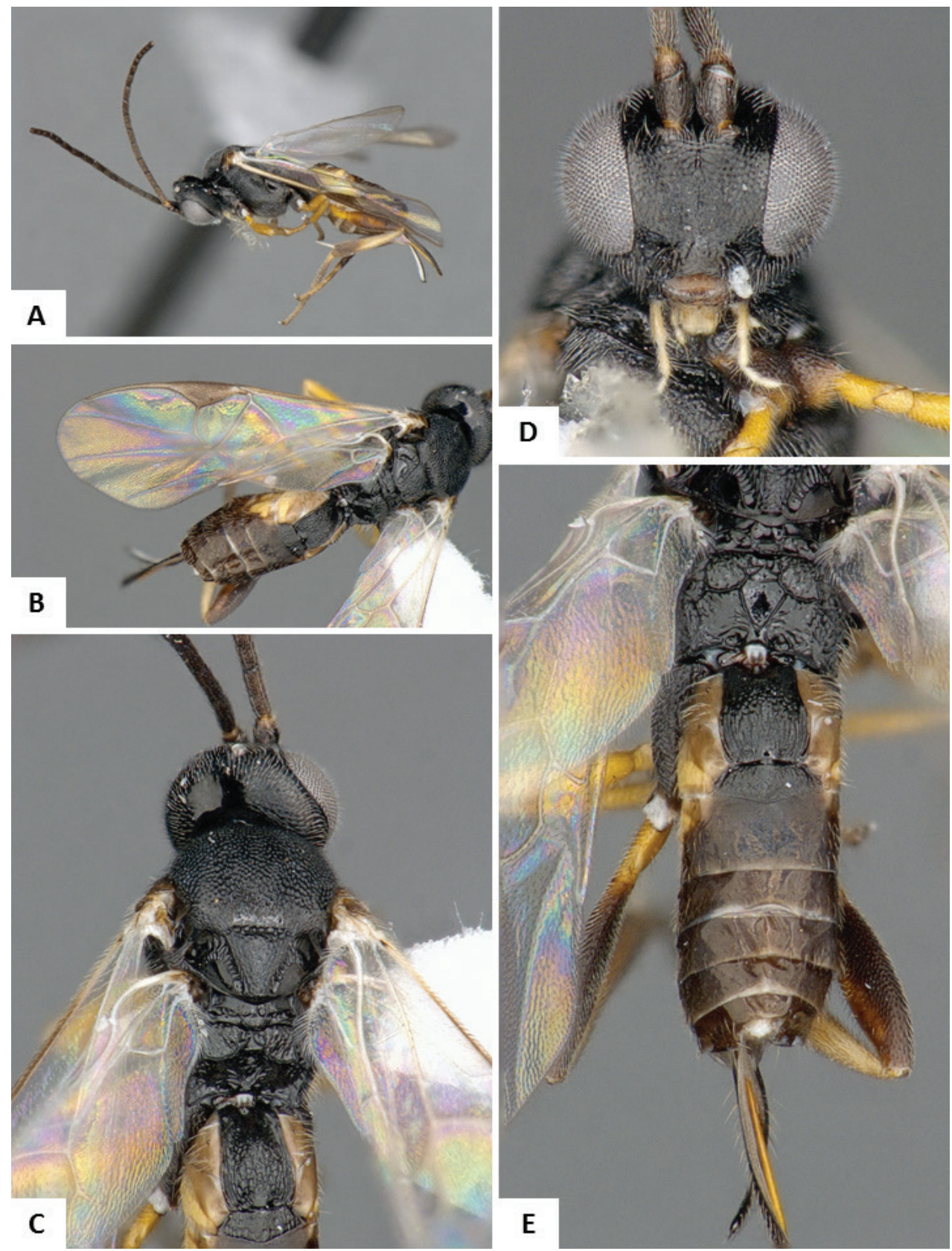

Figure 5. Apanteles hemara female specimen from Kenya (Voucher code: CNC507541). 

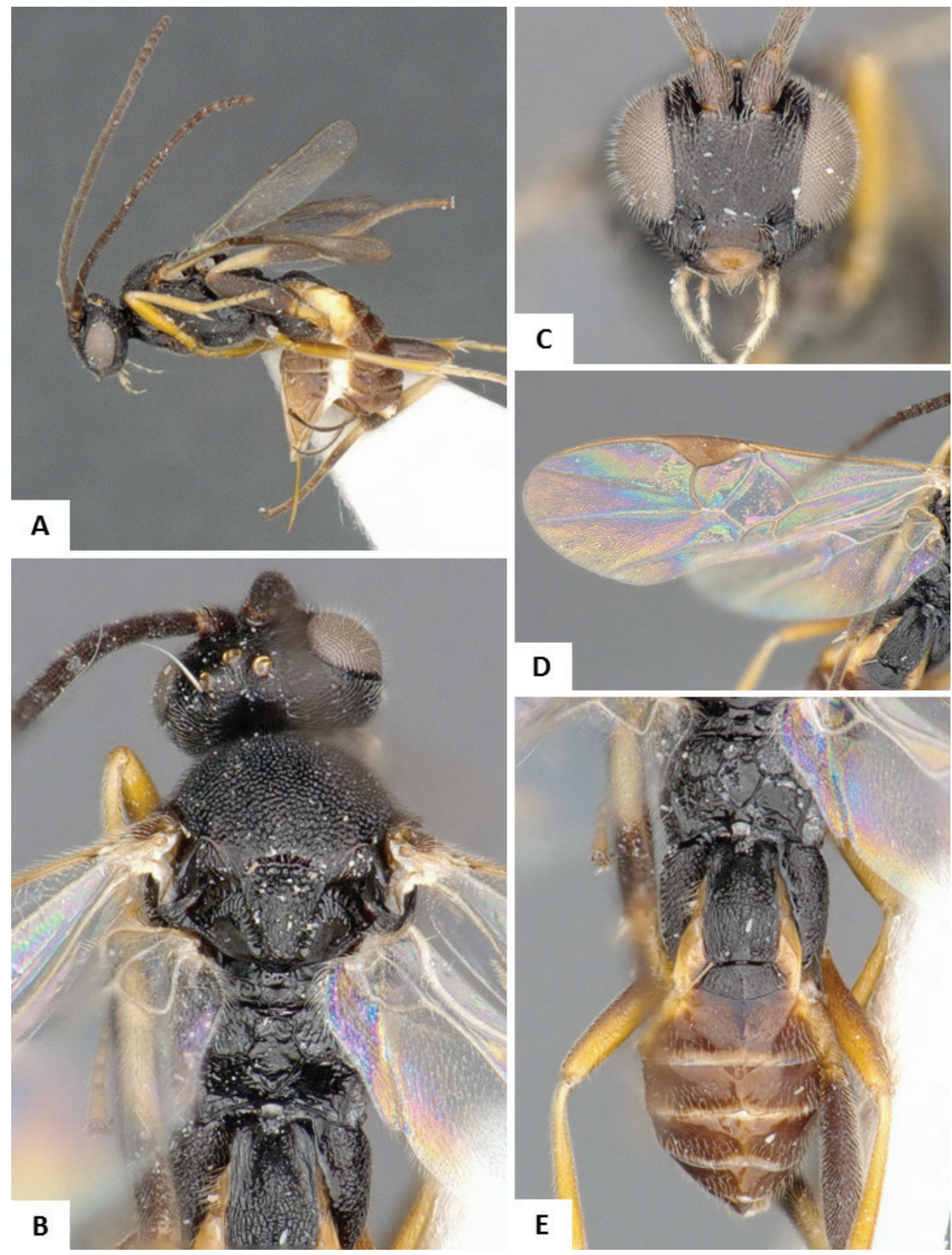

Figure 6. Apanteles hemara female specimen from Yemen (Voucher code: CNC661375). 

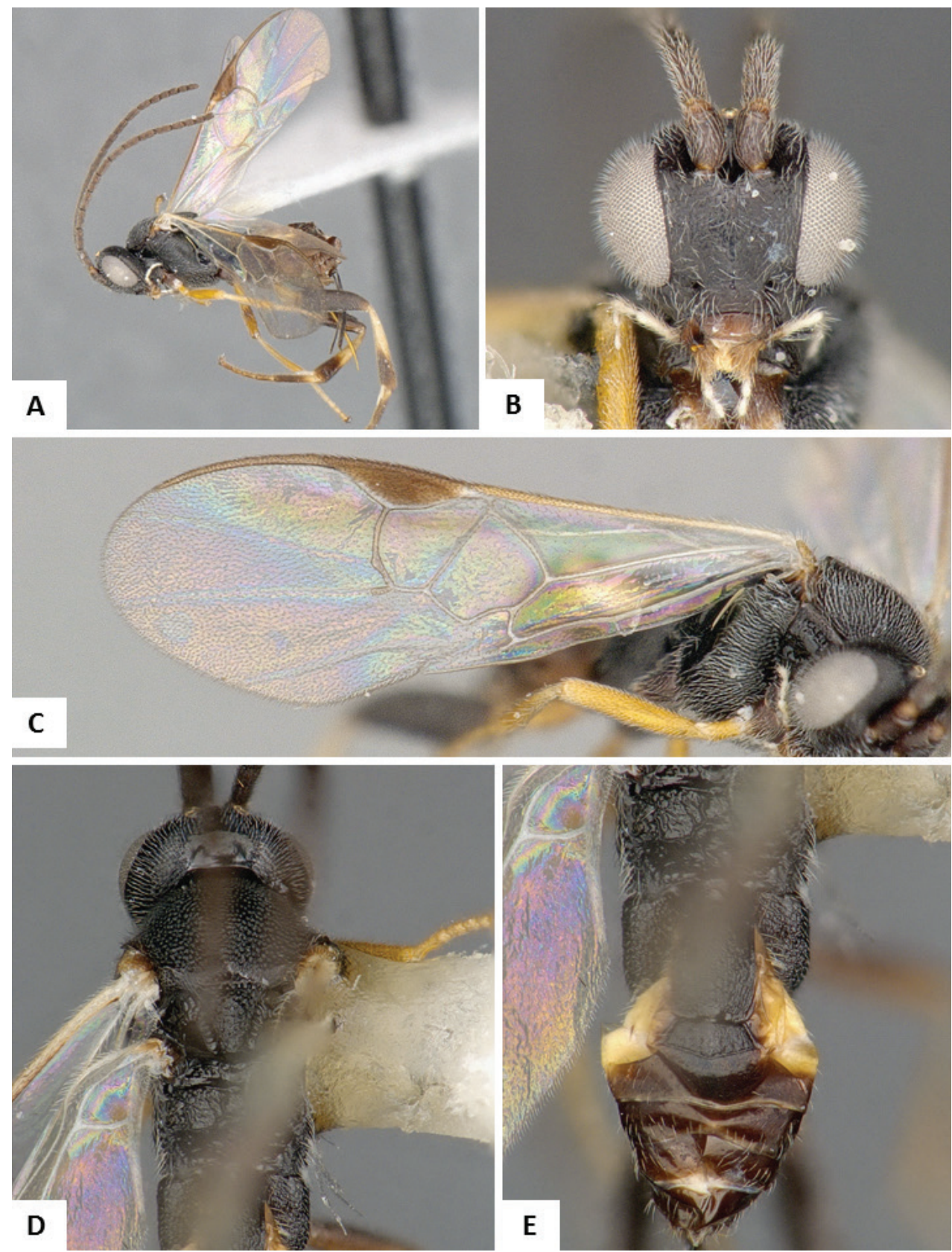

Figure 7. Apanteles hemara female specimen from Madagascar (Voucher code: CNC661376). 
DNA barcodes, expanded distribution, and redescription of Apanteles hemara Nixon...
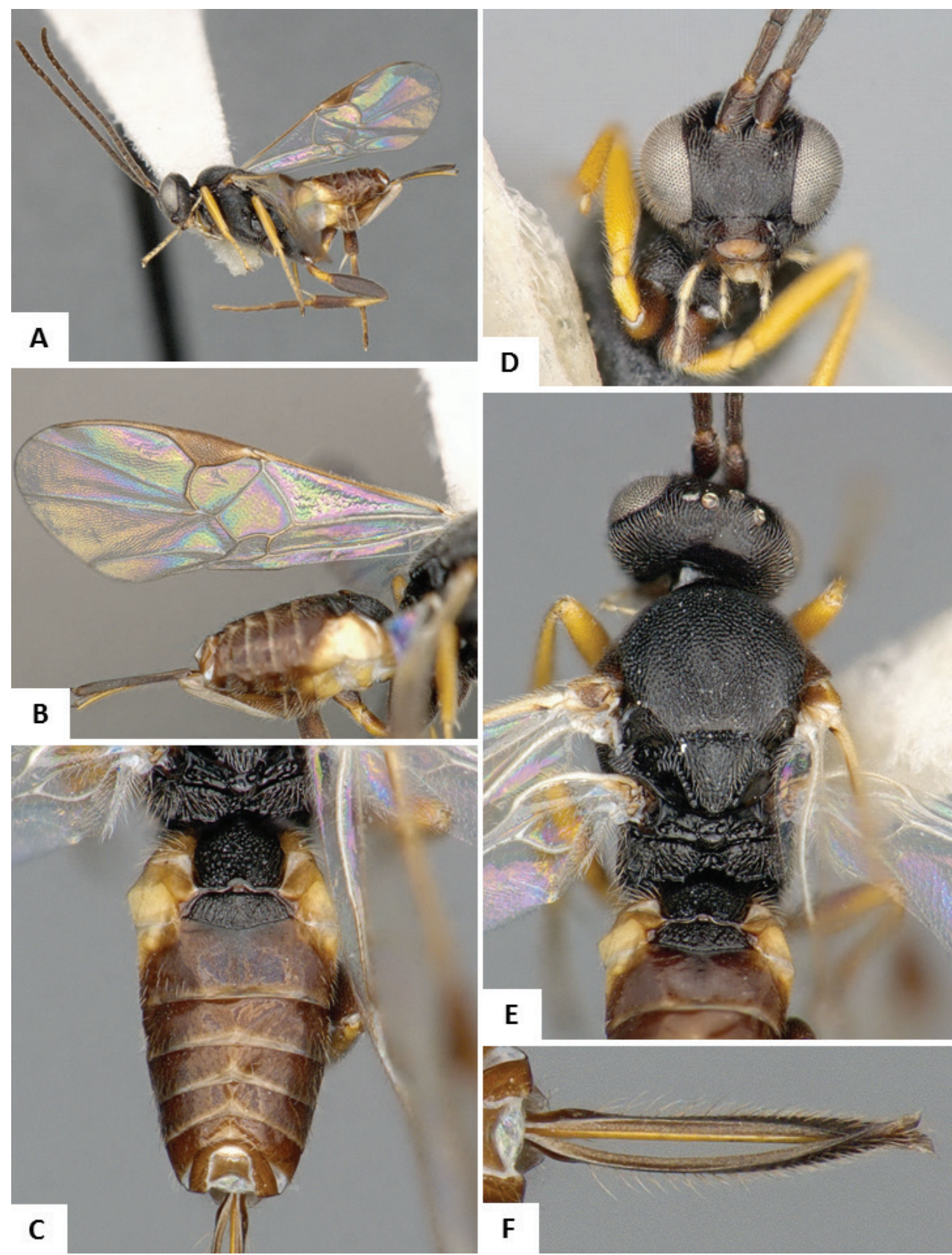

Figure 8. Apanteles hemara female specimen from Oman (Voucher code: CNC661377). 


\section{Acknowledgements}

Gavin Broad (NHM, London, UK) kindly loaned the holotype specimen for study. The research at ICIPE was carried out with financial support from the German Federal Ministry of Economic Cooperation and Development (BMZ).

\section{References}

Arivudainambi S, Selvamuthukumaran T, Baskaran P (2010) Efficacy of herbal extracts in management of amaranth leaf caterpillar. International journal of vegetable science 16(2): 167-173. https://doi.org/10.1080/19315260903375046

Austin AD, Dangerfield PC (1992) Synopsis of Australasian Microgastrinae (Hymenoptera: Braconidae), with a key to genera and description of new taxa. Invertebrate Systematics 6(1): 1-76. https://doi.org/10.1071/IT9920001

Fernandez-Triana J, Whitfield JB, Rodriguez JJ, Smith MA, Janzen DH, Hallwachs W, Hajibabaei M, Burns JM, Solis MA, Brown J, Cardinal S, Goulet H, Hebert PDN (2014) Review of Apanteles sensu stricto (Hymenoptera: Braconidae, Microgastrinae) from Area de Conservación Guanacaste, northwestern Costa Rica, with keys to all described species from Mesoamerica. Zookeys 383: 1-565. https://doi.org/10.3897/zookeys.383.6418

Hebert PDN, Cywinska A, Ball SL, DeWaard JR (2003) Biological identifications through DNA barcodes. Proceedings of the Royal Society B 270: 313-321. https://doi.org/10.1098/ rspb.2002.2218

Ivanova NV, Dewaard JR, Hebert PDN (2006) An inexpensive, automation-friendly protocol for recovering high-quality DNA. Molecular Ecology Notes 6(4): 998-1002. https://doi. org/10.1111/j.1471-8286.2006.01428.x

Kedar SC, Kumaranag KM (2013) Report on outbreak of Spoladea recurvalis (Fabricus) on Trianthema portulacastrum L. and its parasite from Haryana, India. Journal of Entomological Research 37(2): 149-151.

Long KD, Belokobylskij SA (2003) A preliminary list of the Braconidae (Hymenoptera) of Vietnam. Russian Entomological Journal 12(4): 385-398.

Madl M, van Achterberg CA (2014) A catalogue of the Braconidae (Hymenoptera: Ichneumonoidea) of the Malagasy subregion. Linzer Biologische Beitraege 46(1): 5-220.

Nixon G (1965) A reclassification of the tribe Microgasterini (Hymenoptera: Braconidae). Bulletin of the British Museum (Natural History), Entomology series, Supplement 2: 1-284.

Papp J (1980) A survey of the European species of Apanteles Först. (Hymenoptera, Braconidae: Microgasterinae), IV. The lineipes-, obscurus- and ater-group. Annales Historico-Naturales Musei Nationalis Hungarici 72: 241-272.

Papp J (1988) A survey of the European species of Apanteles Först. (Hymenoptera, Braconidae: Microgastrinae). 11. "Homologization" of the species-groups of Apanteles s.l. with Mason's generic taxa. Checklist of genera. Parasitoid/host list 1. Annales Historico-Naturales Musei Nationalis Hungarici 80: 145-175. 
Papp J (2003) Braconid wasps from the Cape Verde Islands (Insecta: Hymenoptera: Braconidae) 2. Doryctinae, Braconinae, Hormiinae, Rogadinae, Gnamptodontinae, Homolobinae, Opiinae, Alysiinae, Cheloninae, Adeliinae and Microgastrinae. Faunistische Abhandlungen (Dresden) 24: 137-167.

Papp J (2007) Braconidae (Hymenoptera) from Greece, 6. Notes fauniques de Gembloux, 60(3): 99-127.

Papp J (2012) A contribution to the Braconid fauna of Israel (Hymenoptera: Braconidae), 3. Israel Journal of Entomology 41(42): 165-219.

Peter C, Balasubramanian R (1984) New records of parasites of Hymenia recurvalis (Lepidoptera: Pyralidae) on Amaranthus. Entomon (India) 9: 71-72.

Ratnasingham S, Hebert PDN (2007) BOLD: The Barcode of Life Data System (www.barcodinglife.org). Molecular Ecology Notes 7: 355-364. https://doi.org/10.1111/j.14718286.2007.01678.x

Shaw MR (2012) Notes on some European Microgastrinae (Hymenoptera: Braconidae) in the National Museums of Scotland, with twenty species new to Britain, new host data, taxonomic changes and remarks, and descriptions of two new species of Microgaster Latreille. Entomologist's Gazette 63: 173-201.

Shorthouse DP (2010) SimpleMappr, an online tool to produce publication-quality point maps. http://www.simplemappr.net [accessed March 10, 2017]

Tobias VI (1986) Keys to the Insects of European Part of the USSR, 3(4) (Hymenoptera, Braconidae). Science Publishers, 52: 94-149.

Velmurugan R, Meenatchi R, Nadarajan L (2006) Lepidopteran Pests and their Natural Enemy Complexes in Amaranth Ecosystem. Biodiversity and Insect Pest Management: 288.

Yu DSK, van C, Horstmann K (2016) Taxapad 2016, Ichneumonoidea 2015. Database on flash-drive. Nepean, Ontario, Canada. http://www.taxapad.com 